\title{
Childhood T Acute Lymphoblastic Leukemia
}

National Cancer Institute

\section{Source}

National Cancer Institute. Childhood T Acute Lymphoblastic Leukemia. NCI Thesaurus.

Code C7953.

An acute lymphoblastic leukemia of T-cell origin occurring in children. 